\title{
Effect of Mask Dead Space and Occlusion of Mask Holes on Delivery of Nebulized Albuterol
}

\author{
Ariel Berlinski MD
}

\begin{abstract}
BACKGROUND: Infants and children with respiratory conditions are often prescribed bronchodilators. Face masks are used to facilitate the administration of nebulized therapy in patients unable to use a mouthpiece. Masks incorporate holes into their design, and their occlusion during aerosol delivery has been a common practice. Masks are available in different sizes and different dead volumes. The aim of this study was to compare the effect of different degrees of occlusion of the mask holes and different mask dead space on the amount of nebulized albuterol available at the mouth opening in a model of a spontaneously breathing child. METHODS: A breathing simulator mimicking infant (tidal volume $\left[\mathrm{V}_{\mathrm{T}}\right]=\mathbf{5 0} \mathrm{mL}$, breathing frequency $=30$ breaths $/ \mathrm{min}$, inspiratoryexpiratory ratio $[\mathrm{I}: \mathrm{E}]=1: 3)$, child $\left(\mathrm{V}_{\mathrm{T}}=155 \mathrm{~mL}\right.$, breathing frequency $=25$ breaths $/ \mathrm{min}, \mathrm{I}: \mathrm{E}=$ 1:2), and adult $\left(V_{T}=500 \mathrm{~mL}\right.$, breathing frequency $=15$ breaths $\left./ \mathrm{min}, \mathrm{I}: \mathrm{E}=1: 2\right)$ breathing patterns was connected to a collection filter hidden behind a face plate. A pediatric size mask and an adult size mask connected to a continuous output jet nebulizer were sealed to the face plate. Three nebulizers were loaded with albuterol sulfate $(2.5 \mathrm{mg} / 3 \mathrm{~mL})$ and operated with $6 \mathrm{~L} / \mathrm{min}$ compressed air for $5 \mathrm{~min}$. Experiments were repeated with different degrees of occlusion $(0 \%, 50 \%$, and $90 \%$ ). Albuterol was extracted from the filter and measured with a spectrophotometer at $276 \mathbf{n m}$. RESULTS: Occlusion of the holes in the large mask did not increase the amount of albuterol in any of the breathing patterns. The amount of albuterol captured at the mouth opening did not change when the small mask was switched to the large mask, except with the breathing pattern of a child, and when the holes in the mask were $50 \%$ occluded $(P=.02)$. CONCLUSIONS: Neither decreasing the dead space of the mask nor occluding the mask holes increased the amount of nebulized albuterol captured at the mouth opening. Key words: mask dead space; face mask; albuterol; nebulizer, breathing patterns; in vitro. [Respir Care 2014;59(8):1228-1232. (0 2014 Daedalus Enterprises]
\end{abstract}

\section{Introduction}

Wheezing illnesses are very frequent in younger children, with almost $50 \%$ of them experiencing a wheezing

\footnotetext{
Dr Berlinski is affiliated with the Pulmonology Section, Department of Pediatrics, University of Arkansas for Medical Sciences, and the Pediatric Aerosol Research Laboratory, Arkansas Children's Hospital Research Institute, Little Rock, Arkansas.

This work was supported in part by the University of Arkansas for Medical Sciences College of Medicine Children's University Medical Group Fund Grant Program (036072). The Pediatric Aerosol Research Laboratory at the Arkansas Children's Hospital Research Institute was partially established and receives partial support from the George Endowment for Asthma.
}

Dr Berlinski presented a version of this paper at the American Thoracic episode between birth and $6 \mathrm{y}$ of age. ${ }^{1}$ Infants and children with respiratory conditions are often prescribed nebulized

\footnotetext{
Society 2012 International Conference, held May 18-23, 2012, in San Francisco, California.

Dr Berlinski served as the principal investigator in clinical trials spon-
sored by Johnson \& Johnson, MPEX Pharmaceuticals, Gilead, Philips
Respironics, Genentech, Vertex Pharmaceuticals, AbbVie, Aptalis,
Janssen Pharmaceuticals, and the Therapeutics Development Network
and was the recipient of an unrestricted educational grant from S\&T
Technologies. None of their products are discussed in this manuscript.
}

Correspondence: Ariel Berlinski MD, Pulmonary Section, Department of Pediatrics, University of Arkansas for Medical Sciences, 1 Children's Way, Slot 512-17, Little Rock, AR 72202. E-mail: berlinskiariel@uams.edu.

DOI: $10.4187 /$ respcare. 02978 
bronchodilators. Bronchodilators are used in the treatment of asthma, bronchiolitis, and croup. ${ }^{2,3}$

Clinical studies have demonstrated equal efficacy of inhaled corticosteroids when inhaled via either a mouthpiece or a mask. ${ }^{4,5}$ Other studies performed in pediatric subjects experiencing an exacerbation showed either no difference or better outcomes with a mouthpiece compared with a face mask. ${ }^{6,7}$ The use of a mouthpiece is preferred over a mask because it reduces ocular and facial exposure to inhaled drugs. ${ }^{8,9}$ However, face masks are used to facilitate the administration of nebulized therapy to patients who are unable to use a mouthpiece. Masks of different designs and sizes are commercially available. A previous study demonstrated that a larger dead space of the mask results in less albuterol delivered by pressurized metereddose inhaler (pMDI) to the mouth opening. ${ }^{10}$ Therefore, masks designed to be used with pMDIs should ideally have a low dead space. However, no data are available regarding the effect of face mask dead space and nebulized drug delivery. An understanding of this will provide manufacturers of face masks with guidance for future mask designs.

Face masks used for nebulized drug delivery incorporate holes into their design. These holes decrease ocular and facial impaction, and they prevent rebreathing of exhaled gases. ${ }^{8}$ Many practitioners occlude these holes in an attempt to increase drug delivery despite the lack of evidence to support this practice.

The aim of this study was to evaluate the effect of different degrees of occlusion of the mask holes, different mask sizes (different dead space), and different breathing patterns on the amount of nebulized albuterol available at the mouth opening of a model of a spontaneously breathing child. We hypothesized that occlusion of the mask holes, use of a mask with smaller dead space, and breathing patterns with larger tidal volumes $\left(\mathrm{V}_{\mathrm{T}}\right)$ will increase the amount of nebulized albuterol available at the mouth opening of a model of a spontaneously breathing child.

\section{Methods}

\section{Devices, Albuterol Solutions, and Measurements}

Three units of a continuous output jet nebulizer (UpDraft II Opti-Neb, Teleflex Medical, Research Triangle Park, North Carolina) were tested in the Pediatric Aerosol Research Laboratory of the Arkansas Children's Hospital Research Institute (Little Rock, Arkansas). The nebulizers were operated at $6 \mathrm{~L} / \mathrm{min}$ with wall air.

Two different bottom-loaded masks were studied: AirLife pediatric aerosol mask (small mask, model 1261, Cardinal Health, McGaw Park, Illinois) and adult aerosol mask (large mask, model 1084, Hudson RCI/Teleflex Medical, Research Triangle Park, North Carolina). The dimensions

\section{QUICK LOOK}

\section{Current knowledge}

Aerosolized bronchodilator delivery in children is commonly provided with a mouthpiece or a mask. Reduced mask dead space is associated with improved efficiency of drug delivery when coupled with a metered-dose inhaler. The presence of holes in the mask and occlusion of these holes may also impact drug delivery.

\section{What this paper contributes to our knowledge}

In a pediatric model of spontaneous breathing, neither reduced mask dead space nor occluding the holes in the mask increased the amount of nebulized albuterol available at the mouth opening when a continuous output jet nebulizer was used.

(dead volume, height, width, and depth) were $75 \mathrm{~mL}, 7.5 \mathrm{~cm}$, $7.5 \mathrm{~cm}$, and $4 \mathrm{~cm}$ for the small mask and $130 \mathrm{~mL}, 10.5 \mathrm{~cm}$, $9 \mathrm{~cm}$, and $6 \mathrm{~cm}$ for the large mask (Fig. 1). Dead volume was measured by a water-displacement technique. ${ }^{11}$

A new ampule of albuterol sulfate $(2.5 \mathrm{mg} / 3 \mathrm{~mL}$; Nephron Pharmaceuticals, Orlando, Florida) was used for each of the runs. Albuterol was quantified via a spectrophotometer at $276 \mathrm{~nm}$ (BioMate $3 \mathrm{UV}-\mathrm{Vis}$, Thermo Fisher Scientific, Waltham, Massachusetts). ${ }^{10}$

\section{Breathing Simulation}

A Pari Compass breath simulator (Pari Pharma, Munich, Germany) was used to mimic different breathing patterns. The device consists of a computer-controller syringe that allows programming of $\mathrm{V}_{\mathrm{T}}$, inspiratory time, breathing frequency, and length of simulation. ${ }^{10}$ Three different breathing patterns corresponding to an infant $\left(\mathrm{V}_{\mathrm{T}}=50 \mathrm{~mL}\right.$, breathing frequency $=30$ breaths $/ \mathrm{min}$, inspiratory-expiratory ratio $[\mathrm{I}: \mathrm{E}]=1: 3)$, child $\left(\mathrm{V}_{\mathrm{T}}=\right.$ $155 \mathrm{~mL}$, breathing frequency $=25$ breaths $/ \mathrm{min}, \mathrm{I}: \mathrm{E}=$ $1: 2)$, and adult $\left(\mathrm{V}_{\mathrm{T}}=500 \mathrm{~mL}\right.$, breathing frequency $=15$ breaths/min, I:E = 1:2) were tested.

\section{Study Design}

The test setup was optimized to minimize confounding factors such as face contour, face mask seal, and force applied to the system. Each mask was glued to a face plate that had a mouth opening (22-mm diameter connector) followed by a low-dead space filter holder that was connected in line with a breathing simulator (Fig. 2). ${ }^{10}$ 


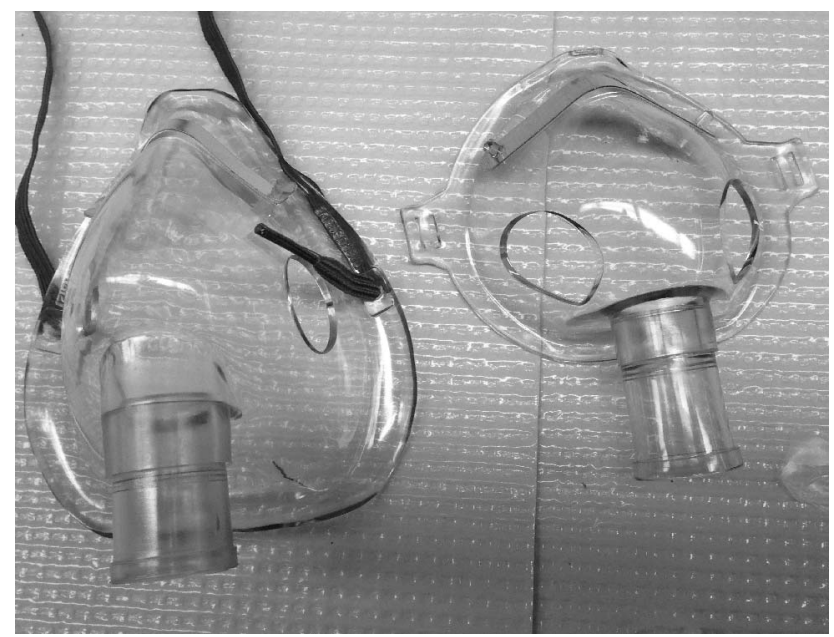

Fig. 1. Masks used in the study.

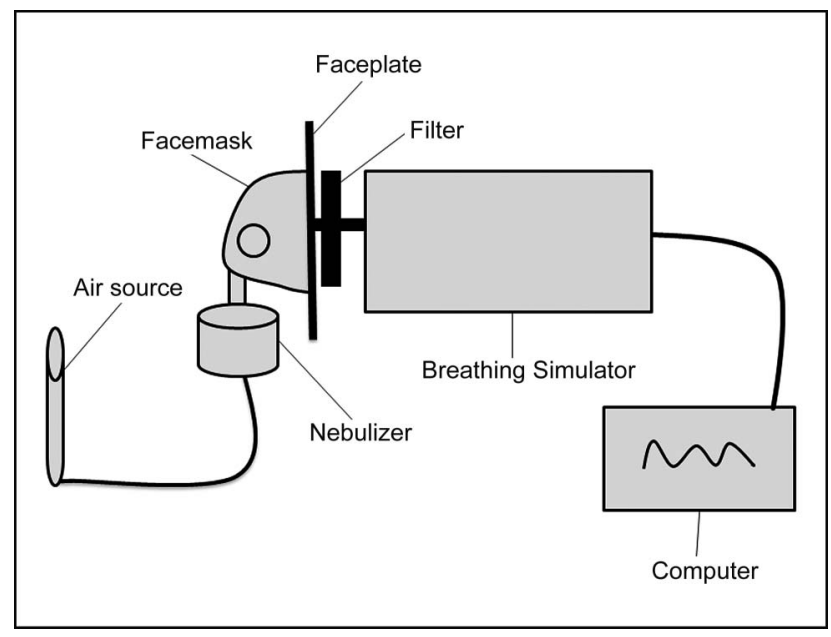

Fig. 2. Setup used for simulated breathing.

\section{Study Protocol}

Nebulizers were weighed on a precision scale before $\left(\mathrm{W}_{\mathrm{D}}\right)$ and after loading $2.5 \mathrm{mg} / 3 \mathrm{~mL}$ albuterol solution. A new filter (Pari Respiratory Equipment, Midlothian, Virginia) was placed in the filter holder, and a specific breathing pattern was programmed in the breathing simulator. The accuracy of the inhaled $\mathrm{V}_{\mathrm{T}}$ was verified with a mass flow meter (model 4043, TSI, Shoreview, Minnesota) and its associated software. The nebulizer was connected to the face mask and operated for $5 \mathrm{~min}$. The nebulizer was reweighted upon completion, ultrapure water $(5 \mathrm{~mL})$ was added to the nebulizer, and a new weight measurement was obtained $\left(\mathrm{W}_{+5}\right)$. Albuterol concentration was measured via a spectrophotometer in the washings, and the albuterol mass remaining in the nebulizer was calculated as follows: $\left(\mathrm{W}_{+5}-\mathrm{W}_{\mathrm{D}}\right) \times$ (albuterol concentration determined by spectrophotometry in $\mu \mathrm{g} / \mathrm{mL}$ ). These results were used as quality controls to ensure that any differences were not due to a difference in output and are not reported. The filters were placed in a 50-mL plastic tube; ultrapure water $(10 \mathrm{~mL})$ was added; and after vigorous shaking, the washings were tested for albuterol concentration via a spectrophotometer. The mass of albuterol captured at the mouth opening was the outcome variable and was calculated as follows: (albuterol concentration from filters) $\times 10$. Nebulizers were thoroughly cleaned with ultrapure water and air-dried. These measurements were repeated while occluding 50\% and $90 \%$ of the surface of the mask holes.

Three different nebulizers were tested with each mask size (small and large) with all 3 breathing patterns (infant, child, and adult) and with 3 different degrees of obstruction of the mask holes $(0 \%, 50 \%$, and $90 \%)$.

\section{Statistics}

Comparison among different breathing patterns and among different degrees of obstruction of the mask holes was done with repeated-measures analysis of variance followed by the Bonferroni test when multiple-comparison analysis was required. Comparison between mask sizes for each breathing pattern was done with a paired $t$ test. $P<.05$ was considered statistically significant.

\section{Results}

\section{Occlusion of the Mask Holes}

Occlusion of the holes in the large mask did not increase the amount of albuterol with any of the breathing patterns $(P=.74, P=.97$, and $P=.80$ for adult, child, and infant, respectively) (Table 1 ).

Occlusion of the holes in the small mask did not increase the amount of albuterol with any of the breathing patterns $(P=.10, P=.02$ [but not significant after a Bonferroni adjustment], and $P=.90$ for adult, child, and infant, respectively). The amount of albuterol available at the mouth was $100 \%$ larger for the child and adult breathing patterns than for the infant breathing pattern.

\section{Mask Size}

The amount of albuterol captured at the mouth opening did not change when the small mask was switched to the large mask for almost all breathing patterns and degrees of obstruction (Fig. 3). The only exception was with the breathing pattern of a child and with the holes in the mask occluded by $50 \%(P=.02)$.

\section{Discussion}

In this study, we found that neither decreasing the dead space of the mask nor occluding the mask holes increased 
Table 1. Amount of Albuterol Captured at the Mouth Opening With Different Degrees of Occlusion of the Mask Holes

\begin{tabular}{lccc}
\hline \hline & \multicolumn{3}{c}{ Degree of Occlusion } \\
\cline { 2 - 4 } Breathing Pattern & $0 \%$ & $50 \%$ & $90 \%$ \\
\hline Small mask & & & \\
$\quad$ Infant & $104 \pm 10$ & $108 \pm 9$ & $104 \pm 9$ \\
$\quad$ Child & $201 \pm 7$ & $225 \pm 11$ & $199 \pm 12$ \\
$\quad$ Adult & $187 \pm 5$ & $217 \pm 13$ & $203 \pm 22$ \\
Large mask & & & \\
$\quad$ Infant & $112 \pm 31$ & $108 \pm 4$ & $103 \pm 4$ \\
$\quad$ Child & $198 \pm 12$ & $199 \pm 18$ & $200 \pm 11$ \\
$\quad$ Adult & $214 \pm 7$ & $217 \pm 18$ & $222 \pm 21$ \\
& & & \\
\hline Results are expressed as mean \pm SD $\mu \mathrm{g}$ of 3 samples. & & \\
\hline
\end{tabular}

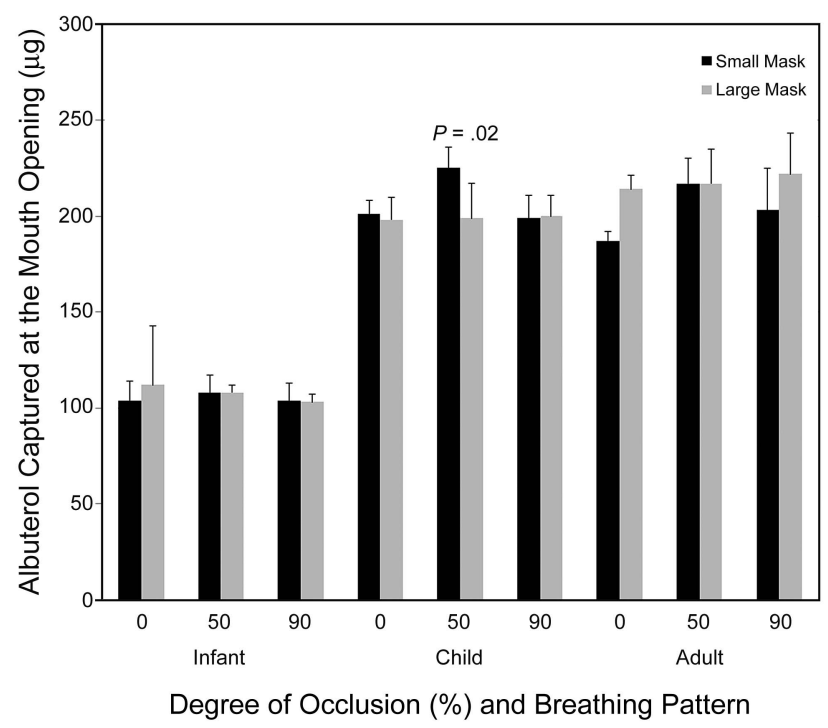

Fig. 3. Amount of albuterol captured at the mouth opening. Results are expressed in $\mu \mathrm{g}$. The bars represent the mean of 3 measurements, and the error bars represent the SD.

the amount of nebulized albuterol captured at the mouth opening. Occlusion of the holes in the mask did not increase the amount of nebulized albuterol available at the mouth opening. These findings reject our first hypothesis. We speculate that occlusion might have increased the pressure inside the mask, negating any potential improvement that the mask behaving like a spacer would provide. The increase in pressure is inferred by the fact that, during the design stage of this study, full occlusion was not possible. In addition, the same amount of exhaled aerosol had to pass through smaller orifices, thus increasing impaction. We speculate that occlusion might have led to an increase in facial deposition. Unfortunately, we did not measure the amount of albuterol deposited on the face plate. Also, occlusion of the mask holes could produce $\mathrm{CO}_{2}$ rebreath- ing. ${ }^{12}$ Therefore, the practice of occluding the holes in a mask should be abandoned.

The amount of albuterol captured at the mouthpiece was lower for the infant breathing pattern, as expected. However, we would have expected the amount of albuterol to be higher with the adult breathing pattern than with the child pattern. The inspiratory flow ([ $\mathrm{V}_{\mathrm{T}} /$ inspiratory time] $\times 60$ ) was $6,11.6$, and $22.5 \mathrm{~L} / \mathrm{min}$ for the infant, child, and adult breathing patterns, respectively. The minute ventilation $\left(\mathrm{V}_{\mathrm{T}} \times\right.$ breathing frequency) was 1.5 , 3.9, and $7.5 \mathrm{~L}$ for the infant, child, and adult breathing patterns, respectively. However, the amount of time/min the aerosol was inhaled (inspiratory time $\times$ breathing frequency) was 15, 20, and $20 \mathrm{~s}$ for the infant, child, and adult breathing patterns, respectively. Therefore, since all inspiratory flows were equal or larger than the nebulizer flow, the difference in the amount of albuterol captured at the mouth was dependent on the exposure time. This would explain why the child and adult breathing patterns rendered similar results. These results are limited to the combination of device and mask most commonly used (continuous output jet nebulizer and bottom-loaded mask). This is in agreement with findings reported by Bauer et al, ${ }^{13}$ who compared nebulized arformoterol output using different breathing patterns. They also found that larger exposure times resulted in larger drug outputs. We anticipate different results with other types of nebulizers such as vibrating mesh nebulizers. ${ }^{14}$ We think that, due to the slow speed of the aerosol produced by the vibrating mesh nebulizer, the breathing pattern plays a major role in drug delivery when this technology is used.

Reduction of the dead space did not affect the amount of nebulized albuterol available at the mouth opening. These findings disprove our second hypothesis and are not in agreement with published data using pMDIs and holding chambers. ${ }^{10}$ That study used a similar experimental setup to the one used in this study, thus eliminating the type of model as a confounding factor. We speculate that the different behavior noted for nebulized albuterol is due to the fact that the aerosol produced by a nebulizer is continuously produced, whereas the aerosol produced by a pMDI is available for inhalation for only a few seconds. Also, the mask might act as a small reservoir, therefore minimizing the negative effect of increasing the dead space.

One of the limitations of this study is the in vitro nature of the testing. Although widely accepted, the filter overestimates the amount of drug delivered by the aerosol generator because it does not allow exhalation of the aerosols. Also, we tested only one type of nebulizer (continuous output) and one type of mask design. As discussed above, results obtained with one type of device/mask should not be extrapolated to others. 


\section{Mask Dead Space and Nebulized Albuterol}

\section{Conclusions}

Contrary to what happens with pMDIs, the mask dead space does not affect the amount of nebulized albuterol available at the mouth opening when a continuous output jet nebulizer and a bottom-loaded mask are used. Also, occlusion of the holes in the mask does not increase the amount of nebulized albuterol available at the mouth opening when a continuous output jet nebulizer and a bottomloaded mask are used. This practice should be abandoned.

\section{REFERENCES}

1. Martinez FD, Wright AL, Taussig LM, Holberg CJ, Halonen M, Morgan WJ. Asthma and wheezing in the first six years of life. The Group Health Medical Associates. N Engl J Med 1995;332(3): 133-138.

2. Schweich PJ, Smith KM, Dowd MD, Walkley EI. Pediatric emergency medicine practice patterns: a comparison of pediatric and general emergency physicians. Pediatr Emerg Care 1998;14(2):89-94.

3. McCulloh RJ, Smitherman SE, Koehn KL, Alverson BK. Assessing the impact of national guidelines on the management of children hospitalized for acute bronchiolitis. Pediatr Pulmonol 2013 [Epub ahead of print] doi:10.1002/ppul.22835

4. Mellon M, Leflein J, Walton-Bowen K, Cruz-Rivera M, Fitzpatrick S, Smith JA. Comparable efficacy of administration with face mask or mouthpiece of nebulized budesonide inhalation suspension for infants and young children with persistent asthma. Am J Respir Crit Care Med 2000;162(2 Pt 1):593-598.

5. Georgitis JW, McWilliams B, Cruz-Rivera M, Fitzpatrick S, Smith JA. Effective once-daily administration of budesonide inhalation sus- pension by nebulizer with facemasks or mouthpieces for persistent asthma in infants and young children. Pediatr Asthma Allergy Immunol 2001;15(1):3-13.

6. Lowenthal D, Kattan M. Facemasks versus mouthpieces for aerosol treatment of asthmatic children. Pediatr Pulmonol 1992;14(3): 192-196.

7. Kishida M, Suzuki I, Kabayama H, Koshibu T, Izawa M, Takeshita $\mathrm{Y}$, et al. Mouthpiece versus facemask for delivery of nebulized salbutamol in exacerbated childhood asthma. J Asthma 2002;39(4): 337-339.

8. Sangwan S, Gurses BK, Smaldone GC. Facemasks and facial deposition of aerosols. Pediatr Pulmonol 2004;37(5):447-452.

9. Geller DE. Clinical side effects during aerosol therapy: cutaneous and ocular effects. J Aerosol Med 2007;20(Suppl 1):S100-S108; discussion S109.

10. Chavez A, McCracken A, Berlinski A. Effect of face mask dead volume, respiratory rate, and tidal volume on inhaled albuterol delivery. Pediatr Pulmonol 2010;45(3):224-229.

11. Shah SA, Berlinski AB, Rubin BK. Force-dependent static dead space of face masks used with holding chambers. Respir Care 2006; 51(2):140-144

12. Mundt C, Sventitskiy A, Cehelsky JE, Patters AB, Tservistas $M$, Hahn MC, Juhl G, Devincenzo JP. Assessing modeled $\mathrm{CO}_{2}$ retention and rebreathing of a facemask designed for efficient delivery of aerosols to infants. ISRN Pediatr 2012;2012:721295.

13. Bauer A, McGlynn P, Bovet LL, Mims PL, Curry LA, Hanrahan JP. The influence of breathing pattern during nebulization on the delivery of arformoterol using a breath simulator. Respir Care 2009; 54(11):1488-1492.

14. Waldrep JC, Dhand R. Advanced nebulizer designs employing vibrating mesh/aperture plate technologies for aerosol generation. Curr Drug Deliv 2008;5(2):114-119. 